\title{
Schizophrenia as a psychosomatic illness: An interdisciplinary approach between Lacanian psychoanalysis and the neurosciences
}

\author{
Yorgos Dimitriadis, MD, PhD
}

According to Lacan's theory of schizophrenia (as well as other delirious forms of psychosis), under certain conditions the signifying function breaks down, thus turning the schizophrenic individual's world into one in which a number of events become enigmatic and signal him or her. The schizophrenic individual tries to deal with these signs that besiege him or her either by means of an interpretative attitude (a stable delusional mood) or by apathy. These two types of responses correspond with the stereotypical (and mood) processes by which the schizophrenic individual attempts to avoid the distress provoked by the enigmatic desire of the Other, while simultaneously corresponding with psychosomatic processes of the brain organ. (Bulletin of the Menninger Clinic, 81[X], 1-18)

To the best of my knowledge, Gustav Jung (2001) was the first to see the possibility of psychosomatic involvement of the central nervous system in schizophrenia, although he did not formulate his concept in these words. Jung felt that the brain, disturbed by tumultuous conflicts, would produce toxins that in their turn would damage the nervous system. It was Silvano Arieti (1959) who first posed this question explicitly in his Handbook

\footnotetext{
Yorgos Dimitriadis, MD, PhD is an assistant professor at the Research Center for Psychoanalysis and Society, EA3522, UFR Psychoanalytic Studies, University ParisDiderot Sorbonne-Cité, Paris, France. He is a psychiatrist/psychoanalyst member of the Association Lacanienne Internationale and works in Paris and Athens, Greece (private practice) as a psychoanalyst and psychiatrist.

Correspondence may be sent to Yorgos Dimitriadis, MD, PhD, Department of Researches in Psychoanalysis, Paris-Diderot University, 8, rue Albert Einstein, 75013, Paris, France; e-mail: dimitriadisyorgos@gmail.com (Copyright @ 2017 The Menninger Foundation)
} 
of Psychiatry. And also later in his book Interpretation of Schizophrenia, he (1974) formulated this view even more explicitly:

whereas every organ or system of the body ... has been recognized as affected by many psychosomatic disorders, the central nervous system has been given only secondary consideration. Could it not be that under certain psychological stress a more or less specific functional disintegration of habitual neuronal patterns takes place? ... A psychosomatic involvement of the central nervous system would require a mechanism different from those responsible for other psychosomatic conditions. In other words, the process would not originate through the action of the autonomic nervous system upon the organs of the body ... the conflicts or turmoils themselves would disrupt the organization of complicated neuronal patterns. (p. 474)

From a Jacksonian perspective, ${ }^{1}$ which also incorporates psychodynamic principles, Arieti (1974) asserted, with regard to schizophrenia, the following:

This neuronal reintegration may thus be seen deterministically and also adaptationally or restitutionally. In fact that seems to be a psychosomatic attempt to return to lower levels of integration, levels that do not permit complicated interpersonal symbolism and long circuited anxiety.... For instance, when logical thinking is impaired, paleologic thinking comes to surface. When social symbols disappear, paleosymbols replace them. Concepts become more and more perceptual, and anticipation of the future is replaced by thoughts concerning the present.... With comparatively few exceptions this attempt fails because the process engenders other self perpetuating mechanisms that lead to regression. (pp. 485-488)

I believe the heuristic notion of "psychosomatic affections of the brain" is actually even more conceivable by virtue of the evolution of psychoanalytic theory and through the advent of

1. John Hughlings Jackson (1835-1911) had postulated that the higher centers of the brain inhibited the lower ones and hence lesions thereat caused "negative" symptoms (due to an absence of function). "Positive" symptoms were caused by the functional release of the lower centers. This process Jackson called "dissolution," a term he borrowed from Herbert Spencer. 
neuroplasticity theories. Francois Ansermet and Pierre Magistretti (2007) have extensively worked (focusing on the question of the trace) on the possible dialogue between Lacanian psychoanalysis and theories of neuroplasticity. I attempt the dialogue between Lacanian psychoanalytic theory and the neurosciences in this article in regard to psychosomatic participation of the brain in schizophrenia. The filtering of perceptions and mood changes in schizophrenia will be the focus of this article.

The symbolic and the psychic apparatus

It seems to me that in order to create a space for psychosomatic illnesses of the brain organ, it is necessary to search beyond the familiar assimilation that we tacitly make between the brain and the psychic apparatus. Nevertheless, this confusion is common and even reinforced by certain reductionist theories advanced by the neurosciences. In this case, how do we define the psychic apparatus? Freud (1908/1959) explicitly defined the psychoneuroses as dependent upon complexes of unconscious representations, thus, I think, that we could say as a process of specific symbolic operations. Psychoneuroses use these symbolic operations while actual neuroses short-circuit them. The mechanism of symptom formation of actual neuroses would be, according to Freud, somatic rather than symbolic, as he spoke $(1895 / 1962)$ of a direct transformation of the excitation in anxiety or neurovegetative symptoms. For Lacan, these symbolic operations of the unconscious are operations that have a language structure. But, as such, they exceed the boundaries of the locus of the language field of any particular individual. However, they are not less real based upon the fact that they do not have a locus exclusive to the neuronal system of a particular individual. This is because they are situated in relation to the Other. $^{2}$

2. Lacan (1971) said signifiers are matter in suspension. A symptom, in the Lacanian psychoanalytical sense of the term, always exists in relation to the Other. It is a form of addressing the Other, a question posed to the Other, while at the same time it leaves a trace, a precipitation of jouissance for the human organism. Perhaps firstly for the brain, although not exclusively. 
How is this conceivable? I think it is possible to comprehend in the same way that we concede, and have done so for quite some time now, that for the most part the developmental plan of a human newborn's brain exists outside the organism; which is to say that the brain's epigenetic development program is inscribed in the social environment upon which its development depends; yet at the same time, it is definitely a neuronal modification. Oliver Sacks (1989) claimed that neither language nor the most elevated structures of the brain appear spontaneously; they depend on exposure to language, communication, and appropriate use of language. Stéphane Thibierge (2007) chooses this formulation:

There exists heterogeneity of registers that cannot be reduced although the neurosciences claim to be capable of doing so. The brain's functioning depends on the structure and the physiology of neurons whereas psychic functioning depends on language structures, symbolic and exterior to the individual's brain. It is evident that the structures have a material effect on concrete subjects and thus localizable cerebral inscriptions.... What psychoanalysis brings to light here concerns how, for the subject, representation supposes the reference to a desire of the Other, in other words, a place that is at once exterior to the subject but that also fundamentally determines it. (pp. 70-71)

Consequently, I believe it is possible to make the assumption that the development of the human brain also requires the existence of a program built into the social structure, one that precedes the person's coming into the world. Is the same not conceivable for illnesses that depend on our social structures (that are in fact signifying structures)? Of course what I am speaking of here is what is commonly known as psychopathology.

The symbolic as man's semiotic system is not the same type as other species' communication systems because the dimension of the Other has a completely different function. As Jean-Marie Vidal (2011) postulates, the semiotic that governs man is a triadic semiotic, and the same does not apply to other animals for which a certain signal refers to a certain object that is present because this communication is dyadic, binary. To this ef- 
fect, Lacan (1953/2006a) said that "the function of language in speech is not to inform but to evoke" (p. 247). The function of evocation is perhaps even more specific for certain linguistic productions, such as unconscious formations and poetry. What influence does all of this have on what we commonly call psychopathology? Tim Crow (who distinguished also between two types of schizophrenia in 1980: Type 1 with positive signs and Type 2 with negative signs; see Crow, 1980) postulates that schizophrenia was made possible the moment man became human by language. Crow's (2000) exact formula goes as follows: "schizophrenia is the price Homo sapiens pays for language" (p. 118). Even more precisely, he supposes, in the same vein, that the genes in connection with schizophrenia are related to the genes that enable language. Following Crow's (2000, 2002) train of thought, language and the schizophrenic individual are two sides of the same coin; and Lacan (1946/2006c) specified the same in the speech he delivered at Bonneval, dating back to 1946, where he claimed that the human species cannot be understood without madness. Elsewhere in an article on the possible treatment of psychosis, Lacan (1956/2006d) said, in regard to President Schreber's process of psychosis, "the only organicity that is essentially involved in this process: the organicity that motivates the structure of signification" (p. 477).

But for all that, do we explain the difference between mental illnesses and neurological disorders? This is a question we consider crucial because lately certain positions (e.g., Price, Adams, \& Coyle, 2000; Yudofsky \& Hales, 2002) are toward closing the divide between psychiatry and neurology. Perhaps we can conceive of a neuropathology for mental illnesses, but a neuropathology for a neurological disorder is not comparable to another that has its main program, that has the same structure with the "structure of signification." Within the limits of this article, I can only treat this process in schizophrenia, which will also be another way to privilege the dialogue with some cognitive theories, which have been greatly preoccupied with the psychopathology of schizophrenia during the past three decades. 
Elements of the Lacanian theory of psychosis

I will begin by reminding the reader of some elements of Lacan's first (until 1960) psychoanalytical theory of psychosis. I'll start with the mirror stage. In his reading of Bolk's foetalization theory, Lacan (1949/2006b) retained its emphasis on somatic retardation of the human newborn, that is, the fact that the human being develops mature adult features such as teeth, body hair, and so on at a later stage than his or her evolutionary ancestors, entailing a prolonged period of infantile dependency. The neural axons of the human newborn are not yet fully developed and therefore initially the infant does not perceive its body as unified through the proprioceptive channel. Starting from the age of 6 months, the infant perceives a unified image of itself, first in the mirror or in others, before actually sensing this unity itself by the proprioceptive channel. The mirror image as well as the infant's reflection in others creates an external reference, enabling the infant to make sense of its own image. The image creates sense retroactively and also constitutes a base for the deflection of the specular I into the social I, for which the naming function by the Other, the other that also has to do with language and law, is so crucial: The baby does not recognize itself simply because of its resemblance to the other (its image in the mirror or the other's body image) but also because of the speech of the Other, who by "naming him" (Lacan, 1960/2006e, p. 568), confirms this project while simultaneously differentiating the baby from the image.

The name, and the symbolic in general, inscribes the baby in a story that surpasses in scope the instantaneity of self-recognition in the mirror. As Dany Nobus (2000) comments: "This implies that the father and the mother need to let the child know in no uncertain terms that they are subjected to a symbolic order which they cannot alter or control" (p. 18). This work is usually realized through the medium of the paternal function as a reference for the desire of the mother. In this manner, the desire of the mother obtains a reference beyond the child itself, a kind of double meaning: desire not only for the child but also for something beyond the child. The access to the symbolic 
has to do with this access to this ambiguity of the desire of the Other, firstly of the maternal Other. Thus, this maternal Other through her reference to the father as the law of her desire and, generally speaking, her reference to the law (for instance the prohibition of incest), gives the child access to the "Name-ofthe-father" (paternal metaphor) and the symbolic in general (Lacan, 1956/2006d). While the Name-of-the-Father operates on the desire of the mother, it also allows access to contextuality, to a deepening of the image. A sense of reality depends on this depth, which also provides the possibility for historicizing, the possibility of an existence beyond the synchrony of specifically body sensations and the instantaneity of the image of the other present here.

The sense given by the image propelled by the effect of the symbolic, as described thus far, also has for effect the exclusion of certain body sensations. I see, I hear, I feel through a filter of the senses. This is the reason why when I perceive selectively through my "unconscious body-image," it is thus simultaneously through my symbolic identity and the context of my presence. This is because the image has symbolic coordinates, as I said earlier, and it is an image that is contextualized. ${ }^{3}$ I need only commit a transgression in the field of my symbolic coordinates (and this is a common experience even for ordinary people) for the imaginary field to start wavering. This is derealization: the Umbeimlich, Freud's (1919/1955) strangely disturbing familiar. For psychotic individuals, the Name-of-the-Father did not operate on the desire of the mother and to this regard the symbolic is deficient. Psychotic individuals have great difficulties when they are compelled to articulate an "I" that goes beyond simple mirror recognition, for example, as soon as they need to situate themselves in their own genealogy as a unique effect rather than the redundancy of another. The encounter with a person or situation that actualizes this question for them can have precisely this effect on the psychotic person.

3. Arnold Modell (2003) also formulated that perception of a feeling, in contrast to sensation, consists of a process in which the sensation is linked to memory and metaphor, providing it with contextual information. Metaphor mediates, categorizes, and thus organizes the perception of bodily sensations (p. 145). 
As a result, psychotic individuals will have a tendency to fixate on some identifications or to have disturbances to the body image. This is morbid narcissism. With the paranoiac individual, for example, the image of others serves as a container for his or her drives. The disorganized schizophrenic individual perceives the parts, "the objects," of his or her own body as foreign. Hallucinations (cenesthetic, voices and otherwise) are the perception of these objects. That is to say, filtering perceptions are quite problematic for individuals with psychosis. Bruce Fink (2007) has already spoken from a psychoanalytic point of view about the difficulty psychotic individuals have in filtering perceptions:

This research seems to be borne out ... by the many cases of "sensory overload" reported by psychotic patients, in which voices that had previously been unheard or that had blended into the background begin to become overwhelming.... The moment at which these perceptions begin to impinge on such subjects is often a very stressful one... In certain autistic and schizophrenic subjects, on the other hand, difficulty filtering stimuli can be permanent ... the difficulty does not come and go as it does in paranoia, where breaks may be followed by apparent remission and then further trouble at a later date. (p. 18)

Here I will consider the "permanent difficulty filtering stimuli" in schizophrenic individuals as a psychosomatic involvement of the brain and more precisely as a mood disorder. Certain neuroscientific theories could be a helpful lead in this direction.

Cognitive theories of schizophrenia and psychoanalysis

How can we reflect on the cognitive theories of schizophrenia from the doctrinal premises of psychoanalysis? There are several cognitive conceptualizations on schizophrenia, as we know. Some of them deal with the filtering of information like the theory of Gray, Feldon, Rawlins, Hemsley, and Smith (1991). Moreover, there is a disregard for context, which is the case for the theory of Cohen and Servan-Schreiber (1993) and likewise for the "Versailles team" (Hardy-Baylé, 2004). I intend 
to discuss what I consider to be of psychoanalytical interest in these theories. We have already seen how impaired recognition, the question of context, and that of filtering sensations, which I have placed particular emphasis on, are very present in the Lacanian psychoanalytical theory of psychoses. However, we encounter these questions in a number of cognitive conceptualizations of schizophrenia as well, questions that were evidently posed from a very different perspective.

But before considering the possible similarities between psychoanalytical concepts and cognitive theories, we should take the necessary precaution of specifying some important differences:

- Cognitive theories view schizophrenic disorders as synchronic, that is to say, cut off from the subject's history and outside the conditions required for their manifestation.

- Neither does the desire of the Other, including the person who examines the patient, factor in.

- For the most part, these theories consider that there is a failure of a neuronal circuit.

- The presumed organicity of the disorders is most often viewed by cognitive theories through a functionalist prism, in other words, as a neurological disorder of the integrative modules of the brain.

I believe that cognitive theories are mistaken when they objectify to the exclusion of all subjectivity. But I also think that the minute description that they utilize-which includes neuropsychological tests-may offer us clinical elements and-why not-grist for the psychoanalytical mill. But before this discussion, I will speak of something that these theories have not touched upon. As regards psychoanalytical theory, the failure to assume one's own image, and because of this the particularities in the filtering of perceptions for the schizophrenic individual, always depend on the symbolic context, and they are not static abilities or "modules." In a "normal" case, the assumption of the image also varies, and there exist different phenomena of depersonalization in the psychopathology of everyday life, as I 
said before. I mean to say that the unfolding of events always actualizes the "dialogue" between the imaginary on one side and the symbolic on the other. This explains why on top of the fact that the precipitation of a psychosis has specific symbolic coordinates, the psychotic individual's failure to assume his or her image arises even after the psychosis is triggered, which is to say in a selective manner-for example, in one context rather than another. I mean to say that breaks in the train of thought, hallucinations among many other psychotic phenomena, are related to context. This is an issue that cognitive theories do not really deal with. Sometimes they take marginal notice in their studies (when they say, for instance, that psychotic individuals have difficulties with words with double meanings), but they do not really study context per se (i.e., difficulties with a specific context for a specific subject), and there is an explanation for this: Their method objectifies, that is, generalizes, as scientific methods do.

However, there are clinical phenomena that psychoanalytical theory cannot take up either, or if so, only peripherally. For example, we know that the schizophrenic individual often displays chronic disorders that do not depend entirely on a particular context, such as blunted affect, mannerisms, and stereotypes that are mostly stable traits over time and that we generally call residual symptoms. On the other hand, certain aspects of acute phases tend to be automatic and are independent of the symbolic coordinates that trigger them. I am speaking of, for example, psychomotor excitation or a general interpretative attitude. These phenomena are frequently independent of context or become so over a relatively lengthy period of time. Neuroscientists proclaim that we can diagnose certain disturbances through electrophysiological exams, neuropsychological tests, functional brain imagery, and other examinations. How could psychoanalysis view this? I think the notion of a psychosomatic disorder of the brain could be a helpful lead in this direction. In schizophrenia the foreclosure of the Name-of-the-Father, as I stated earlier, generates instability in the symbolic function that risks coming undone. After the psychosis is triggered, the symbolic falling away has repercussions on the body image and 
gives way to problems of thinking about what others think. The schizophrenic individual, especially the disorganized one, has tremendous difficulty hypothesizing about the viewpoint of others. Therefore, the question regarding the desire of the Other (and the jouissance) becomes anxiety-ridden. That is to say, in this case the the topographical regression (Lacan, 1956/2006d) of the schizophrenic to the mirror phase implies the undoing of the triadic structure, already fragile after foreclosure-which was in a way also pseudo-triadic - and the setting up of a logic of signs, thus a dyadic logic. The world sends the schizophrenic individual back the "signification of signification," and according to Lacan (1956/2006d), "the effect of signification anticipates the development of signification therein" (pp. 451-452). Or as Lacan (1932/1975) had already stated in his thesis, it is a moment when the form and content of signification cannot be distinguished and are thus formal significations. In other words, only the form of signification remains. We could say that at this moment the world for the psychotic individual contains signs of significations that are nevertheless devoid of any content. For Lacan (1956/2006d), this phase concerns "an effect of the signifier, insofar as its degree of certitude (second degree: signification of signification) takes on a weight proportional to the enigmatic void that first presents itself in the place of signification itself" (p. 451). In his doctoral thesis, Lacan (1932/1975) qualified this phase as the almost "pure affective state"; I quote: "where intellectual elaboration is reduced to the perception of a personal signification" (p. 137).

I will approach the matter from the perspective of this initial affect, which a number of authors, such as Karl Jaspers (1913/1997), have also underlined as delusional mood (Wabnstimmung), According to this approach, during the initial phase, there is a sort of overload of signifying signs, and this constitutes a particular affective state. I believe we could say that this first particular affective state (as it is related to the sign overload) triggers another more automatic, more stable state that is also more independent of the Other as a result. This other state will be either a desensitization, facing this overcharge, or conversely, a sensitization, which we might call an "accomplished mood." 
This is to say that what results will occur either by means of physiological desensitization ${ }^{4}$ toward affective indifference (athymormia, ${ }^{5}$ also called apathy, blunted affect), or, by means of a physiological sensitization, toward a pure affect (in other words. a kind of mood). This means that there is an attempt to emotionally disaffect, to detach from the Other, either by apathy or by a stable delusional mood. Both imply a stereotypical attitude and a negativism toward the desire of the Other. Of course this attitude is not the "self cure" by means of organized delusion that Freud (1911/1958) had claimed for paranoia; but it is another kind of "self-cure." At the same rate, paranoia can be distinguished from paranoid schizophrenia (and generally speaking schizophrenic individuals' paranoid ideas): We have organized delusions in paranoia, and we can have (but not always) stable delusional mood without (or with a little only) organization in schizophrenia. However, I think that these two mechanisms (stable delusional mood and athymormia) represent a psychosomatic evolution of schizophrenic psychosis.

Next, I will hypothesize the compatibility of this phenomenon, which I indeed qualify as psychosomatic, with some conceptualizations of neurobiology and cognitive theories:

- This last idea on mood changes in schizophrenia is probably compatible with Richard Davidson's (1994) statement: "Mood serves as a primary mechanism for altering information-processing priorities and for shifting modes of information processing" (p. 52).

- Jaak Panksepp (1998) made the supposition according to which one of the "basic emotional systems of man" that he

\footnotetext{
4. We have an interesting indirect confirmation of this idea from Lacan's presentation on psychical causality at Bonneval (1946/2006c): "I would not hesitate to say that one could demonstrate that the Oedipal crisis has physiological echoes, and that, however purely psychological its mainspring may be, a certain "dose of Oedipus" can be considered to have the same humoral efficacy as an absorption of a desensitizing medication" (p. 149).

5. The concept of athymormia of the French psychiatrist Paul Guiraud (1950) could be more specific regarding the problem that schizophrenic individuals have to be selfactivated than the terms blunted affect, apathy, or affective indifference that are more usually used for schizophrenia. Some authors such as Luauté and Saladini (2001) tend to confuse athymormia in schizophrenic individuals with symptoms of apathy in some neurological syndromes.
} 
Schizophrenia as a psychosomatic illness

named seeking system is hypersensitized in paranoid schizophrenia. Under normal circumstances, this system is activated in order to seek causal correspondences between correlated environmental events (e.g., those that that occur simultaneously). It is a system to which the author ascribes an adaptive value and which, according to Panksepp, has to do with causal thinking by analogy in man. Chronic use of psychostimulants, such as amphetamines and cocaine, reacts on the system and sometimes provokes paranoid ideation, says the author. When this system (which utilizes neurotransmitters such as dopamine) becomes free running, it can generate delusional thoughts that are actually an exaggeration of the normal capacity of the brain to make connections between events occurring simultaneously. Panksepp makes the supposition that for the paranoid schizophrenic individual, Crow's Type 1 stress can activate the dopaminergic system, which then becomes hyposensitized, and in turn the seeking system is activated to eliminate the source of stress. But according to the author, this would have the effect of producing paranoid ideas because the person jumps to conclusions too quickly. Here again we see how Panksepp questions a sensitization mechanism for generating a free running state in paranoid schizophrenia as well as in the chronic use of psychostimulants. Another strategy, adaptation by approximation, consists of adopting an identical response to the different stimuli because they are regarded as equal on the basis of surface similarities. Hemsley (1987) considers stereotypical responses and delusional ideas to be the consequences of this second adaptive mechanism.

- I think that in a similar manner with the previous views, Shitij Kapur and David Mamo ${ }^{6}$ (2004) proposed that in psychosis a deregulated dopamine transmission leads to stimulus-inappropriate release of dopamine, that is, a normally neutral stimulus results in the firing of neurons in the mesolimbic system. This neurochemical aberration usurps the normal process of salience attribution, leading to aberrant assign-

6. More recently, Jim van Os (2009) expressed similar ideas from a epidemiological point of view. 
ment of salience to external objects or internal representations. Thus, dopamine, which under normal conditions is a mediator of contextually relevant salience, in the psychotic state becomes a creator of salience, albeit an aberrant one. The dopamine system, according to the authors, normally attributes priority to novel situations, be they rewarding or aversive in nature, and this attribution of salience is based on past experience and predispositions. It is proposed that neuroleptics are efficacious in psychosis because (by their pharmacological actions involving the mesolimbic dopaminergic system at some level) they "dampen salience" of the subjective experience of delusions and hallucinations. Along with dampening the salience of symptoms, some normal-life saliences may also get dampened, perhaps leading to what is often called neuroleptic-induced dysphoria or drug-induced negative/depressive symptoms. In that way, for the authors, antipsychotics are dampening psychosis and not excising it.

- I think that Daniel Widlöcher (1997) also agrees with this hypothesis when he argues that a neuroleptic's action is rather to diminish the overcharge in information. In that way, the subject can more easily cope with the weak capacity that he or she has to treat the information.

\section{Conclusions}

In conclusion, concerning the interdisciplinary approach between psychoanalysis on the one hand and cognitive psychopathology and the neurosciences on the other, I cannot express my position more succinctly than in the words of Jean-Marie Vidal and Sylvie Tordjmann (2006): "The only reasonable criterion is that a theory be firstly appropriated by its proper field and secondly that it not be incompatible with the most established theories in the neighbouring field that cross-check it in part" (p. 156).

The existence of a neuropathology in schizophrenia, be it contingent (as clinical and laboratory data argue for) or even 
necessary (although this has not been demonstrated), hardly excludes the notion that the semiotic structure is decisive for the setting up of a psychotic structure in infancy or in the emergence of psychosis in adulthood precisely when the deficiency (set up in childhood) becomes actual, as described earlier. Certain neuropathological processes, possibly responsible for a part of the symptomatology of schizophrenia, could be considered from this point of view to be a psychosomatic process that, once in motion, follows a relatively autonomous course compared to the symbolic process that triggered it. In this way, we can separate neurological from psychiatric diseases, which becomes difficult from the point of view of most new theories of mental illness.

This course seems to be related to mood processes, which the terms delusional mood or athymormia can at least partially explain. These terms also represent states of relative stability for the psychotic individual because in these conditions the individual does not depend on the desire of the Other. More precisely, these states are stereotypical modes of response to the presence of this desire.

As regards their trajectory, these mood processes depend on neuroplasticity mechanisms of sensitization or desensitization. These neurobiological mechanisms hypothetically are connected to the genome; thus-theoretically-biological vulnerability could be, in part, related to them.

Other types of psychosis-like paranoia do not have the same type of psychosomatic evolution, and they are, from this standpoint, more pure in their symptomatology. In this case, the psychotic individual remains more dependent on symbolic processes. Organized delusion (rather than disassociated, as in the case of delusional mood) is a part of these symbolic processes and, as Freud (1911/1958) stipulated, in this respect it constitutes an attempt at a cure precisely because it can also lead to the pacification of anxiety facing the desire (and the jouissance) of the Other. But mood processes such as stable delusional mood and athymormia could be other ways of pacification in psychoses. 


\section{References}

Ansermet, F., \& Magistretti, P. (2007). Biology of freedom: Neural plasticity, experience, and the unconscious (S. Fairfield, Trans.). New York, NY: Other Press.

Arieti, S. (Ed.). (1959). American handbook of psychiatry. New York, NY: Basic Books.

Arieti, S. (1974). Interpretation of schizophrenia (2nd ed.). New York, NY: Basic Books.

Cohen, J. D., \& Servan-Schreiber, D. (1993). A theory of dopamine function and its role in cognitive deficits in schizophrenia. Schizophrenia Bulletin, 19, 85-104.

Crow, T. J. (1980). Molecular pathology of schizophrenia. British Medical Journal, 280(6207), 66-68.

Crow, T. J. (2000). Schizophrenia as the price that Homo sapiens pays for language: A resolution of the central paradox. Brain Research Reviews, 31, 118-129.

Crow, T. J. (Ed.). (2002). The speciation of Homo sapiens. New York, NY: Oxford University Press.

Davidson, R. J. (1994). On emotion, mood, and related affective constructs. In P. Ekman \& R. J. Davidson (Eds.), The nature of emotion: Fundamental questions (pp. 51-55). New York, NY: Oxford University Press.

Fink, B. (2007). Fundamentals of psychoanalytic technique: A Lacanian approach for practitioners. New York, NY: W. W. Norton.

Freud, S. (1955). The "uncanny." In J. Strachey (Ed. \& Trans.), The standard edition of the complete psychological works of Sigmund Freud (Vol. 17, pp. 217-256). London: Hogarth Press. (Original work published 1919)

Freud, S. (1958). Psycho-analytic notes on a auto-biographical account of a case of paranoia (dementia paranoides). In J. Strachey (Ed. \& Trans.), The standard edition of the complete psychological works of Sigmund Freud (Vol.12, pp. 1-82). London: Hogarth Press. (Original work published 1911)

Freud, S. (1959). "Civilized" sexual morality and modern nervous illness. In J. Strachey (Ed. \& Trans.), The standard edition of the complete psychological works of Sigmund Freud (Vol. 9, pp. 177-204). London: Hogarth Press. (Original work published 1908)

Freud, S. (1962). On the grounds for detaching a particular syndrome from neurasthenia under the description "anxiety neurosis." In J. Strachey (Ed. \& Trans.), The standard edition of the complete psychological works of Sigmund Freud (Vol. 3, pp. 85-117). London: Hogarth Press. (Original work published 1895) 
Schizophrenia as a psychosomatic illness

Hardy-Baylé, M. C. (2004). Clinique comprehensive [Comprehensive clinical study]. In C. Spadon (Ed.), Les schizophrénies [The schizophrenias] (pp. 40-52). Paris, France: PIL.

Hemsley, D. R. (1987). An experimental psychological model for schizophrenia. In H. Hafner, W. F. Gattaz, \& W. Janzarik (Eds.), Search for the causes of schizophrenia (pp. 179-188). Berlin, Germany: SpringerVerlag.

Gray, J. A., Feldon, J., Rawlins, J. N. E., Hemsley, D. R., \& Smith, A. D. (1991). The neuropsychology of schizophrenia. Behavioral and Brain Sciences, 14, 1-84.

Guiraud, P. (1950). Psychiatrie générale [General psychiatry]. Paris, France: Le François.

Jaspers, K. (1997). General psychopathology. Baltimore, MD: Johns Hopkins University Press. (Original work published 1913)

Jung, C. G. (2001). The psychogenesis of mental disease. New York, NY: Pantheon Books.

Kapur, S., \& Mamo, C. (2004). Why antipsychotics are anti-'psychotic'. In C. McDonald, K. Schultze, R. M. Murray, \& P. Wright (Eds.), Schizophrenia: Challenging the orthodox (pp. 113-126). London, England: Taylor \& Francis.

Lacan, J. (1971). Lituraterre. Littérature, 3, 3-10.

Lacan, J. (1975). De la psychose paranö̈aque dans ses rapports avec la personnalité [Paranoiac psychosis and its relation to personality]. Paris, France: Seuil. (Original work published 1932)

Lacan, J. (2006a). The function and field of speech and language in psychoanalysis. In B. Fink (Trans.), Ecrits [Writings] (pp. 237-268). New York, NY: W.W. Norton. (Original work published 1953)

Lacan, J. (2006b). The mirror stage as formative of the I function. In B. Fink (Trans.), Ecrits [Writings] (pp. 74-81). New York, NY: W.W. Norton. (Original work published 1949)

Lacan, J. (2006c). Presentation on psychical causality. In B. Fink (Trans.), Ecrits [Writings] (pp. 123-158). New York, NY: W.W. Norton. (Original work published 1946)

Lacan, J. (2006d). On a question prior to any possible treatment of psychosis. In B. Fink (Trans.), Ecrits [Writings] (pp. 531-488). New York, NY: W.W. Norton. (Original work published 1956)

Lacan, J. (2006e). Remarks on Daniel Lagache's presentation: "Psychoanalysis and Personality Structure." In B. Fink (Trans.), Ecrits [Writings] (pp. 647-584). New York, NY: W.W. Norton. (Original work published 1960)

Luauté, J. P., \& Saladini, O. (2001). Le concept français d'athymhormie de 1922 à nos jours [The French Concept "Athymhormie" from 1922 to the present]. Canadian Journal of Psychiatry, 46, 639-643.

Modell, A. H. (2003). Imagination and the meaningful brain. Cambridge, MA: MIT Press. 
Nobus, D. (2000). Jacques Lacan and the Freudian practice of psychoanalysis. London, England: Routledge.

Panksepp, J. (1998). Affective neuroscience: The foundations of human and animal emotions. New York, NY: Oxford University Press.

Price, B., Adams, R., \& Coyle, J. (2000). Neurology and psychiatry: Closing the Great Divide. Neurology, 54(1), 8-14.

Sacks, O. (1989). Seeing voices: A journey into the world of the deaf. Berkeley, CA: University of California Press.

Thibierge, S. (2007). Clinique de l'identité [Clinical study of identity]. Paris, France: PUF.

van Os, J. (2009). A salience dysregulation syndrome. British Journal of Psychiatry, 194, 101-103.

Vidal, J.-M. (2011). La tierceïté symbolique, fondement de la discontinuité psychique entre animaux et humains [Symbolic thirdness as the foundation of the psychic discontinuity between animals and humans]. Revue Française de Psychanalyse, 20, 17-51.

Vidal, J.-M., \& Tordjmann, S. (2006). Neurologie et psychopathologie de l'autisme. L'illusion étiologique [Neurology and psychopathology of autism: The etiological illusion]. Psychologie Clinique, 20, 43-156.

Widlöcher, D. (1997). Le psyché Carrefour [The psyche as a crossroad]. Paris, France: Georg Eshel.

Yudofsky, S., \& Hales, R. (2002). Neuropsychiatry and the future of psychiatry and neurology. American Journal of Psychiatry, 159, 1261-1264. 